\title{
A DICTIONARY OF NEUROLOGICAL SIGNS
}

CLINICAL NEUROSEMIOLOGY 


\title{
A DICTIONARY OF NEUROLOGICAL SIGNS
}

\section{CLINICAL NEUROSEMIOLOGY}

\author{
A.J. LARNER \\ MA, MD, MRCP(UK), DHMSA \\ Walton Centre for Neurology and Neurosurgery, \\ Liverpool, U.K.
}

KLUWER ACADEMIC PUBLISHERS

NEW YORK, BOSTON, DORDRECHT, LONDON, MOSCOW 
eBook ISBN: $\quad 0-306-47505-7$

Print ISBN: $\quad 1-4020-0043-X$

(C)2002 Kluwer Academic Publishers

New York, Boston, Dordrecht, London, Moscow

Print C2001 Kluwer Academic Publishers

Dordrecht

All rights reserved

No part of this eBook may be reproduced or transmitted in any form or by any means, electronic, mechanical, recording, or otherwise, without written consent from the Publisher

Created in the United States of America

Visit Kluwer Online at: http://kluweronline.com

and Kluwer's eBookstore at: http://ebooks.kluweronline.com 
To myparents 
Lexicographer: a writer of dictionaries; a harmless drudge, that busies himself in ... detailing the signification of words.

- Samuel Johnson. A Dictionary of the English Language. 1755

Lexicographer: a pestilent fellow who, under the pretence of recording some particular stage in the development of a language, does what he can to arrest its growth, stiffen its flexibility, and mechanize its methods.

- Ambrose Bierce. The Devil's Dictionary. 1911 


\section{CONTENTS}

Foreword by Martin N. Rossor

ix

Preface by the author

xi

Acknowledgements

$\mathrm{XV}$

A

1

B

C 43

D 57

E

73

F

79

G

90

H

95

I

113

J

118

$\mathbf{K}$

121

L

124

M

129

$\mathbf{N}$

142

O

149

P

157

Q

181

$$
\text { - vii - }
$$




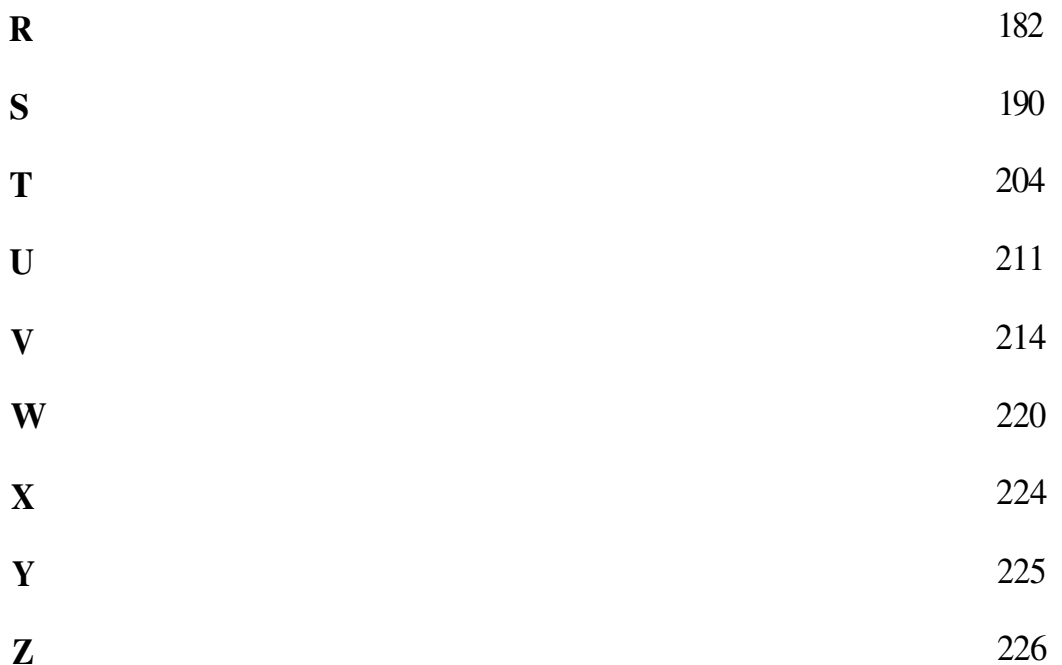




\section{FOREWORD}

Neurology has always been a discipline in which careful physical examination is paramount. The rich vocabulary of neurology replete with eponyms attests to this historically. The decline in the importance of the examination has long been predicted with the advent of more detailed neuroimaging. However, neuroimaging has often provided a surfeit of information from which salient features have to be identified, dependent upon the neurological examination. A dictionary of neurological signs has a secure future.

A dictionary should be informative but unless it is unwieldy, it cannot be comprehensive, nor is that claimed here. Andrew Larner has decided sensibly to include key features of the history as well as the examination. There is no doubt that some features of the history can strike one with the force of a physical sign. There are entries for "palinopsia" and "environmental tilt" both of which can only be elicited from the history and yet which have considerable significance. There is also an entry for the "head turning sign" observed during the history taking itself as well as the majority of entries relating to details of the physical examination.

This book is directed to students and will be valuable to medical students, trainee neurologists, and professions allied to medicine. Neurologists often speak in shorthand and so entries such as "absence" and "freezing" are sensible and helpful. For the more mature student, there are the less usual as well as common eponyms to entice one to read further than the entry which took you first to the dictionary.

Martin N. Rossor

Professor of Clinical Neurology

National Hospital for Neurology and Neurosurgery

Queen Square

London 


\section{PREFACE}

In writing a book devoted to neurological signs and their meaning, it is not my intention to undervalue in any way the skill of neurological history taking. This remains the key element of the doctor-patient encounter both in the neurological clinic and on the ward, and is clearly crucial in order to formulate diagnostic hypotheses, guide clinical examination, and help decide on the nature of the pathological process (if one is present). However, having sat through several thousand neurological consultations, I do not subscribe to the view that all one need do is listen carefully and the patient will "tell you the diagnosis", although this may happen on rare (and often memorable) occasions. Clearly, history taking is not simply a passive recording of symptoms ("what the patient complains of"), but also an active process of seeking information of possible diagnostic significance through appropriate questions; this might be called the "historical examination". This latter facet of history taking, much the more difficult skill to learn, may disclose certain neurological signs which are not available to physical examination (principally in the sensory domain, but also intermittent motor phenomena). Hence, my use of the term "sign" in this book is a broad one, encompassing not only findings in physical examination (its traditional use) but also from focused history taking. My operational definition of sign is therefore simply a "signifier", in the sense of phenomena of semiologic value, giving information as to anatomical location and/or pathological cause.

Most neurological textbooks adopt an approach which is either symptom-based, beginning with what the patient complains of and then offering a structured differential diagnosis; or disease-based, assuming that a diagnosis has already been established. Although such texts are of great value, it seems to me that this does leave a place for a book devoted to neurological signs. Signs, elicited in either the historical or neurological examination, bridge the gap between the patient's symptoms, and the selection of appropriate investigations to confirm or refute the examiner's diagnostic formulations and thus establish a diagnosis.

Although it has been mooted whether the dramatic technological advances in neurological practice, for example in neuroimaging, might render neurological examination redundant, others maintain the central importance of neurological examination in patient management. ${ }^{1,2}$ It will come as little surprise to the reader that I am emphatically of the latter persuasion. However, this book does not aim to be a handbook of neurological examination technique (one reason for the absence of pictures), or neurological investigation, many excellent examples of which already exist. Rather, it seeks to elucidate the interpretation of neurological signs ("neurosemiology"): their anatomical, physiological, and pathological significance 
(where these are known). It should be added quickly that this is not to suggest that neurological signs are peculiarly objective (as some systems of clerking might suggest): as with all clinical observations, neurological signs are subject to both interand intra-observer variation and are biased by prior knowledge of the history and other examination findings. ${ }^{3-5}$ As with other elements of clinical examination, relatively little study of the accuracy and precision of neurological signs has been undertaken; a methodology to remedy this situation has been suggested. ${ }^{6}$ It is hoped that the current work might encourage more such studies. To those who might suggest that, in an age of molecular genetics, such an undertaking is passé, and rather nineteenth-century in its outlook, I would argue that precision in the definition of clinical signs is of relevance if meaningful genotype/phenotype correlations are to be established.

An attempt has been made to structure the entries in this volume in the following way:

- a definition of the sign, or the common usage of the term (subtypes italicised);

- a brief account of the clinical technique required to elicit the sign;

- a description of other neurological signs which may accompany the index sign (cross referenced as appropriate).

Where known, there is appended:

- a brief account of the neuroanatomical basis of the sign;

- an explanation, where possible, of the pathophysiological and/or pharmacological basis of the sign;

- the neuropathological basis of sign;

- a differential diagnosis of the commonest clinical diseases causing or associated with the sign (bulleted);

- brief details of specific treatments of these disorders, if available.

Using this schema, it will hopefully prove possible to integrate clinical phenomenology with the underlying neuroscience (anatomy, physiology, and pathology) in an accessible manner which will facilitate assimilation by the reader. Clearly not all these factors are known or applicable for every sign, and hence definitions vary quite considerably in length, the longer entries generally being for signs of greater clinical importance. Salient references from the primary and secondary literature are given, particularly for the more uncommon signs, for those wishing to pursue topics further. Entries are cross-referenced to other relevant signs. 
Clearly such an undertaking cannot hope to be (and does not claim to be) comprehensive, such is the diversity of neurological function. Moreover, the limitations of my personal clinical experience means that selections are inevitably somewhat arbitrary, precluding (at the very least!) inclusion of signs familiar in paediatric neurological practice. Dermatological signs of potential neurological relevance have also been largely overlooked, and after much consideration "bruit" has been omitted. Nonetheless, it is hoped that this book will be of use to all students of neurology, both undergraduate and postgraduate, both dedicated neurology trainees and those required, perhaps against their personal inclinations, to develop some familiarity with neurology for examination purposes (e.g. candidates for the MRCP). It may also serve as a book of reference for more experienced clinicians. Since the majority of patients with neurological symptoms and signs in the United Kingdom are currently seen by general practitioners and general physicians, a situation which is likely to persist for some time, if not indefinitely, ${ }^{7}$ it is very much hoped that these groups will also find the book of use, as indeed may members of ancillary professions: nursing, physiotherapy, speech and language therapy, occupational therapy, radiography.

The definitions given are not conceived of as in any way immutable. Language, after all, is plastic with respect to meaning and usage, and my aim is certainly not to "fix" the language. Nor do I suppose, despite my indebtedness to many distinguished colleagues, that I have been free from errors, all of which are my own doing. I shall be happy to hear from those who find errors, disagree with my suggested definitions, or feel that important signs have been omitted.

\section{REFERENCES}

1. Ziegler DK. Is the neurologic examination becoming obsolete? Neurology 1985; 35: 559

2. Caplan LR. The effective clinical neurologist. Oxford: Blackwell Scientific 1990

3. Stam J, van Crevel H. Reliability of the clinical and electromyographic examination of tendon reflexes. Journal of Neurology 1990; 237: 427-31

4. Maher J, Reilly M, Daly L, Hutchinson M. Plantar power: reproducibility of the plantar response. BMJ 1992; 304: 482

5. Hansen M, Sindrup SH, Christensen PB, et al. Interobserver variation in the evaluation of neurological signs: observer dependent factors. Acta Neurologica Scandinavica 1994; 90: 145-9

6. McAlister FA, Straus SE, Sackett DL, on behalf of the CARE-COAD1 Group. Why we need large, simple studies of the clinical examination: the problem and a proposed solution. Lancet 1999; 354: 1721-4

7. Neurology in the United Kingdom: Towards 2000 and beyond. London: Association of British Neurologists 1997 


\section{ACKNOWLEDGEMENTS}

Thanks are due to many individuals for their continuing help and encouragement during the preparation of this text, namely (in alphabetical order): Alasdair Coles (who heroically read and commented on the whole manuscript), Alex Leff, Michael and Sally Mansfield, Parashkev Nachev, and James Rakshi. They have sustained me on the occasions when I have felt that this dictionary, like that of Doctor Strong, would take one thousand six hundred and forty nine years to complete (Charles Dickens, David Copperfield, 1850). I am grateful to Professor Martin Rossor for contributing the foreword, clarifying many points in the text, and also drawing my attention to Samuel Johnson's adage that "Dictionaries are like watches: the worst is better than none, and the best cannot be expected to go quite true" (my hope is that this volume falls within the latter category rather than the former). At Kluwer, Olaf Blaauw's consistent enthusiasm for the project and helpful advice on technical matters have been greatly appreciated. All the errors and shortcomings which remain are entirely my own work.

Thanks are also due to Philippa, Thomas and Elizabeth for their forbearance, because, willy-nilly, "The life of every family is conditioned by the work of its elders; think of a doctor's house, or a writer's ..." (Rumer Godden, The River, 1946). 